\title{
Support persons' preferences for the type of consultation and the format of information provided when making a cancer treatment decision
}

\author{
Anne Herrmann ${ }^{1,25^{*}}$ D , Rob Sanson-Fisher ${ }^{1,2}$, Alix Hall ${ }^{1,2}$, Laura Wall ${ }^{3}$, Nicholas Zdenkowski ${ }^{2,4}$ and Amy Waller ${ }^{1,2}$
}

\begin{abstract}
Objective: Cancer patients and their support persons commonly feel overwhelmed when being confronted with their diagnosis and treatment options. We used a DCE to examine patients' and support persons' preferences for: (i) attending one 40 min consultation or two 20 min consultations when making a cancer treatment decision; and for (ii) receiving additional information in written form only or in both written and online forms. Here we focus on support persons' preferences and whether they differ from patients' preferences.

Results: 159 adult medical oncology patients and 64 of their support persons took part in this study. Participants were presented with a set of hypothetical scenarios and asked to indicate their most and least preferred scenario. $92 \%$ of support persons $(n=59)$ completed the DCE. Most preferred to receive two consultations along with written and online information $(n=30,51 \%)$. This was the only scenario that was chosen by statistically significantly more support persons ( $p=0.037$ ). The proportions of patients and support persons choosing each scenario did not differ significantly from each other ( $p>0.05$ ). Our findings suggest that when making cancer treatment decisions, clinicians should consider offering patients and support persons written and online information, combined with two shorter consultations.
\end{abstract}

Keywords: Cancer, Caregivers, Communication, Neoplasms, Oncology, Patients

\section{Introduction}

Support persons can provide important insights into how to improve treatment decision making

When deciding on their cancer treatment, patients commonly seek help from their partner, family and friends [1]. Patients often value their support persons' involvement in decision making and feel more certain about their decision after consulting their support persons [2]. Most patients want their support persons to have a say about their cancer treatment decisions [3]. Some even prefer their support persons to take the lead in treatment decision making $[4,5]$. However, many support

\footnotetext{
*Correspondence: Anne.Herrmann@uon.edu.au

${ }^{5}$ Health Behaviour Research Group, University of Newcastle, University Drive, W4, HMRI Building, Callaghan, NSW 2308, Australia

Full list of author information is available at the end of the article
}

persons do not understand all the information provided to them or may be psychologically unprepared to hear the patient's prognosis and treatment options [6]. To allow patients and support persons to consider and discuss the information provided during the consultation and facilitate support person involvement in treatment decision making, it has been suggested that they should be provided with two consultations with a short time between each consultation, combined with information presented in multiple formats [7]. Our previous work indicates that patients may prefer this consultation style to receiving one longer consultation and written information only [8]. However, data is lacking on whether support persons share this view. To our knowledge, this is the first study to examine support persons' preferences for (i) the number and length of consultations, and (ii) the format 
of information provided when making a cancer treatment decision; and to assess whether their preferences align with what cancer patients would prefer. Having such data can help ensure that patients and support persons receive the resources they need to make informed healthcare decisions.

\section{Discrete choice experiments (DCEs) to study patients' and support persons' preferences}

DCEs are a methodologically robust approach to assessing people's preferences [9]. In a DCE, participants are presented with a set of hypothetical scenarios and asked to indicate their preferred option [10]. Compared to other methodologies used to elicit people's preferences, DCEs have a number of advantages, including: reduced participant burden as they are only required to consider one single survey item, and elimination of yes-response bias as participants are forced to elicit a preference [11, 12]. There is evidence to support the internal validity and consistency of DCE designs [10]. DCEs have been used across a number of fields, including cancer research. For example, Hol et al. employed a DCE to determine, among people with an average risk of developing colorectal cancer, their preferences for various colorectal cancer screening tests [13]. Sculpher and colleagues used a DCE to establish which prostate cancer treatment attributes are most important to men [14]. DCE designs have been found a valid and reliable approach to elicit patients' preferences for different aspects of cancer care $[15,16]$.

\section{Main text}

\section{Aims}

To examine, in a sample of cancer patient support persons, their preferences for:

i. Attending either one $40 \mathrm{~min}$ consultation or two 20 min consultations when making a cancer treatment decision for themselves; and

ii. The format of information they would receive regarding their treatment options (written vs written and online).

We then compared support persons' preferences to patients' preferences.

\section{Design}

This was a cross-sectional study which included a DCE. Consenting participants completed a paper-and-pen survey via their preferred method (mailed or via email) within 1 week after recruitment (baseline) and 3 months later (follow-up). The DCE assessed in this study was included in the follow-up survey. Patient recruitment, data collection and patients' preferences have been described in detail in a separate paper [8]. Here we are looking at support persons' preferences and whether they differ from patients' preferences. Consenting patients were asked to nominate a support person. If this person accompanied the patient to their appointment, they were approached for consent in the clinic. If the support person was not present in the clinic, consenting patients were provided with a recruitment package which included a study information letter and a survey to pass on to the eligible person.

\section{Sample and setting}

This study was undertaken in two medical oncology treatment centres in NSW, Australia. Eligible support persons were: (i) nominated by the patient as someone helping them cope with their cancer through support, encouragement and communication; (ii) aged 18 years or over; and (iii) English speaking. Clinic staff recorded the age and gender of non-consenters who provided permission, which allowed for examination of consent bias.

\section{Measures}

DCE to examine preferences for consultation type and format of information

The DCE consisted of two attributes with two levels each. Thus, participants were presented with four scenarios (see Fig. 1, [8]). Attributes and levels were based on a literature review and discussions among the research team. The scenarios were shown in a randomly selected order. The DCE was pilot tested with health behaviour researchers, clinicians, statisticians and cancer patients.

\section{Sociodemographic characteristics}

The following self-reported sociodemographic characteristics of support persons were evaluated: age, sex, relationship to patient, whether support persons were living with the patient and the time spent with the patient.

\section{Statistical analysis}

All analyses were conducted in Stata 14.2 and R 3.4.0 (2017-04-21). Consent bias with regard to sex and age were assessed using Chi squared tests. The DCE data was analysed using descriptive statistics, Pearson's Chi squared test with Yates' continuity correction and an ordinal regression model. This enabled us to examine the trade-offs participants made when choosing between the different levels of the attributes. Chi squared tests were used to examine if the proportions of support persons who chose each scenario were statistically significantly different from the proportions of patients choosing each scenario, using a $p$ value cut-off of 0.05 . Bootstrapping was used to calculate $95 \%$ confidence intervals. 
IMAGINE THE FOLLOWING: You have been diagnosed with cancer. Your doctor has told you about different treatment options for your cancer. He has asked you to decide which treatment you would like to have.

\section{IMPORTANTLY:}

- There is no difference between the treatment options in terms of how they will affect your length of life.

- However, the treatment options have different pros and cons. Your doctor believes that it is important that the decision is yours. He is happy for you to have either type of treatment. The decision depends on how you feel about the pros and cons of the options.

o Whichever treatment you choose it will start in two weeks from your first appointment.

We are interested in finding out what you think would help you most in making this decision.

If you were in that situation, which of the scenarios below would you like most? Also, which of the scenarios would you like least?

For each question please choose one option only by ticking one of the relevant boxes.

\begin{tabular}{l|l|c|c|c|}
\hline & $\begin{array}{c}\text { One 40 minute consultation } \\
\text { and written information only }\end{array}$ & $\begin{array}{c}\text { One } 40 \text { minute consultation } \\
\text { and written and online } \\
\text { information }\end{array}$ & $\begin{array}{c}\text { Two 20 minute consultations } \\
\text { and written information only }\end{array}$ & $\begin{array}{c}\text { Two 20 minute consultations } \\
\text { and written and online } \\
\text { information }\end{array}$ \\
\hline $\begin{array}{l}\text { I would like MOST } \\
\text { Please tick one box in } \\
\text { this row: }\end{array}$ & & & \\
\hline $\begin{array}{l}\text { I would like LEAST } \\
\text { Please tick one box in } \\
\text { this row: }\end{array}$
\end{tabular}

Fig. 1 An example of the scenarios support persons could choose from to indicate their most and least preferred consultation type and format of information

\section{Results}

\section{Participants}

One hundred thirteen support persons filled out the baseline survey, of which $74 \%(n=84)$ consented to be sent a follow-up survey. Of these, 64 (76\%) completed the questionnaire. There were no statistically significant differences between consenters and non-consenters in terms of age and gender $(\mathrm{p}>0.05)$. Support persons had a mean age of 61 years. Most support persons were female $(\mathrm{n}=41,64 \%)$ and reported to be the patient's spouse or partner $(n=37,58 \%$, see Table 1$)$. Patients' consent and response rates as well as patient characteristics have been described in detail elsewhere [8].

\section{Support persons' preferences}

Ninety-two percent of support persons $(n=59)$ completed the DCE. Just over half of support persons $(n=30$, $51 \%)$ preferred to receive two consultations combined with written and online information when making a cancer treatment decision for themselves (see Fig. 2). The second most preferred scenario included one consultation and written and online information, with $24 \%$ of support persons $(n=14)$ preferring this option. The third most preferred scenario included one consultation and written information only $(14 \%, \mathrm{n}=8)$. Support persons preferred least to receive two consultations and written information only $(12 \%, n=7)$. The only scenario that was
Table 1 Sociodemographic characteristics of support persons

\begin{tabular}{lc}
\hline & $\begin{array}{l}\text { Respondents } \\
\mathbf{n = 6 4}(\%)\end{array}$ \\
\hline $\begin{array}{l}\text { Age in years, mean (SD) } \\
\text { Gender }\end{array}$ & $61(13)$ \\
Male & $23(36)$ \\
Female & $41(64)$ \\
Relationship to the patient & \\
Spouse/partner & $37(58)$ \\
Relative & $24(38)$ \\
Other & $3(4.6)$ \\
Living with the patient & \\
Yes & $42(66)$ \\
No & $22(34)$ \\
Time spent caring for patient & \\
Less than $20 \mathrm{~h}$ & $31(48)$ \\
$20-40 \mathrm{~h}$ & $10(16)$ \\
More than $40 \mathrm{~h}$ & $10(16)$ \\
Unsure or do not provide any care & $11(17)$ \\
Missing & $2(3.1)$ \\
\hline
\end{tabular}

chosen by statistically significantly more support persons included two consultations and written and online information $(\mathrm{p}=0.037)$. The percentages of support persons 


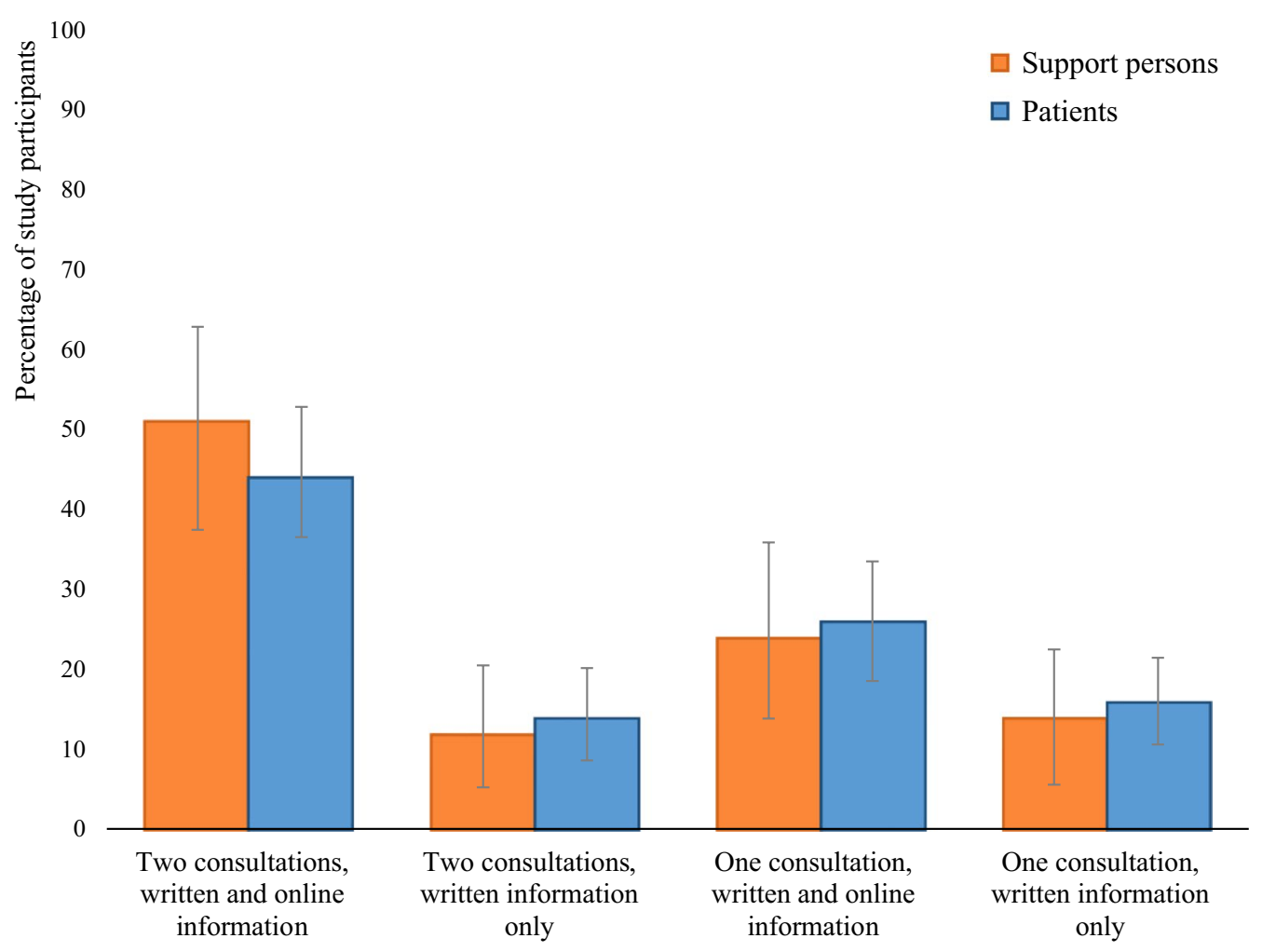

Fig. 2 Patients' and support persons' preferences for scenarios

choosing one of the other scenarios did not differ significantly from each other.

\section{Patients' preferences}

Cancer patients' preferences are presented in detail in a separate paper [8]. Of the 147 patients completing the DCE, most preferred to receive two consultations along with written and online information $(n=65 ; 44 \%$, see Fig. 2). Statistically significantly more patients preferred to receive two shorter consultations over one longer consultation, when this was combined with being provided with additional written and online information $(\mathrm{p}<0.01)$.

\section{Comparing patients' and support persons' preferences}

The proportions of support persons choosing each scenario did not differ statistically significantly from patients' preferences ( $p>0.05$, see Fig. 2).

\section{Discussion}

We examined support persons' preferences for different characteristics of oncology consultations when making a cancer treatment decision, and whether these preferences differed to what patients preferred. Our data indicate that most support persons would prefer to receive two shorter consultations and both written and online information when deciding on their treatment, which was also true for patients. We found no difference in the proportions of support persons' and patients' preferences for the other options. Both patients and support persons seem to be driven by the same preferences for how to make cancer treatment decisions. They appear to prefer to receive information on the available treatment options in multiple formats and would like to have two consultations to make the decision [8]. This might facilitate a shared approach towards decision making between patients, their support persons and treating clinicians by allowing patients and support persons to talk about the information provided by their doctors. Also, receiving information via multiple channels might help patients and support persons access information according to their individual preferences and assist them with comprehending, weighing-up and using the information presented to them during the consultation [17].

\section{Why incorporating patients' and support persons' preferences for how to make treatment decisions}

In order to be patient-centred, healthcare needs to align with patients' preferences and incorporate sociocultural influences, such as support persons' needs and wishes [18]. Our data suggest that patients and their support 
persons may have similar views about how to make cancer treatment decisions. As such, support persons may be a source of information about patients' wishes which could help doctors identify patients' decision making preferences and tailor care accordingly. Also, the importance of support persons for patients' decision making process has been highlighted by a number of health psychology theories, such as the Theory of Reasoned Action and the Theory of Planned Behaviour [19, 20]. These theories suggest that deciding on patient care can be influenced by the so-called "subjective norm" which refers to i) what beliefs the patients think that their support persons hold about the decision at hand, and ii) the extent to which patients are influenced by these others $[19,20]$. Clinicians need to be aware of support persons' role in the decision making process when aiming to support patients with making treatment decisions. Aligning care with patients' and support persons' wishes can improve patient outcomes, for example by reducing conflicts between doctors, patients and support persons [21]. It can further improve patients' recovery from their discomfort and concern, improve their emotional wellbeing and treatment adherence, and ultimately lead to more efficient and effective patient care [22, 23].

\section{Conclusions}

Support persons can play an important role in treatment decision making and their preferences need to be taken into account in order to achieve optimal, patient-centred cancer care [23, 24]. Based on our findings, patients and support persons seem to prefer the idea of having two shorter consultations supplemented with written and online information, rather than one longer consultation and written information alone when making cancer treatment decisions. Offering this consultation style to patients might help involve their support persons in the decision making process and assist patients with making informed decisions regarding their care. Intervention studies are needed to examine how different consultation styles may impact on patients' and support persons' outcomes.

\section{Limitations}

It has been argued that people's preferences for choosing hypothetical scenarios may differ from their preferences for making actual decisions [25]. However, several studies have compared actual choices with stated preferences and found that parameters from both were similar [26]. Also, we examined support persons' preferences with regard to what they would want if they decided on their own cancer treatment. However, they may not have experienced cancer themselves. Consequently, their answer may not reflect what they would prefer if they were faced with this decision. Finally, support persons' preferences for what they would want for themselves may differ from what they would choose when supporting the patient they care for. However, we were interested in how support persons would prefer to make treatment decisions to better understand how we could help them "digest" the provided information and become involved in treatment decision making. Also, it has been suggested that support persons' views on how they prefer to make cancer treatment decisions can impact on the relationship between doctor and patient [21]. Thus, it is important to study support persons' views on what they would choose if they had to decide on their own treatment.

\section{Abbreviations \\ DCE: discrete choice experiment; NSW: New South Wales.}

\section{Authors' contributions}

All authors contributed substantially to the conception and design of this study. AW, NZ and AH1 were involved in the collection and assembly of data. $L W, A H 1, A H 2$ and RSF were involved in carrying out the data analysis. All authors made important intellectual contributions to the interpretation of the data and were involved in drafting the manuscript and revising it critically. All authors are accountable for all aspects of the work. All authors read and approved the final manuscript.

\section{Author details}

1 Priority Research Centre for Health Behaviour, University of Newcastle and Hunter Medical Research Institute, Callaghan, Australia. ${ }^{2}$ School of Medicine and Public Health, University of Newcastle, Callaghan, Australia. ${ }^{3}$ School of Psychology, University of Newcastle, Callaghan, Australia. ${ }^{4}$ Department of Medical Oncology, Calvary Mater Newcastle, Waratah, Australia. ${ }^{5}$ Health Behaviour Research Group, University of Newcastle, University Drive, W4, HMRI Building, Callaghan, NSW 2308, Australia.

\section{Acknowledgements}

We would like to thank our study participants for their time and effort. We also thank Professor Scott Brown for his contribution to the development and analysis of the DCE.

\section{Competing interests}

The authors declare that they have no competing interests.

\section{Availability of data and materials}

Data will be available from the authors upon reasonable request.

\section{Consent for publication}

Not applicable.

\section{Ethics approval and consent to participate}

The Hunter New England Human Research Ethics Committee has granted full ethics approval for this research (approval number: 14/11/19/4.04). Participants gave written informed consent before taking part in this study.

\section{Funding}

Financial support for this study was provided by a Strategic Research Partnership Grant [CSR 11-02] from the Cancer Council NSW to the Newcastle Cancer Control Collaborative (New-3C) and by a Partnership Project [APP1059760] from the National Health \& Medical Research Council (NHMRC). Anne Herrmann is supported by a University of Newcastle, a University of Newcastle/ Hunter Cancer Research Alliance Research Scholarship and has received funding support from the Hunter Cancer Research Alliance Implementation Science Flagship Program as part of the 2017 and the 2018 RHD Award initiative. Nicholas Zdenkowski is supported by the Hunter New England Local Health District. Amy Waller is funded by an Australian Research Council 
Discovery Early Career Research Award. We acknowledge infrastructure funding from the University of Newcastle and Hunter Medical Research Institute. The funding agreement ensured the authors'independence in designing the study, interpreting the data, writing, and publishing the report.

\section{Publisher's Note}

Springer Nature remains neutral with regard to jurisdictional claims in published maps and institutional affiliations.

Received: 15 April 2018 Accepted: 28 June 2018

Published online: 11 July 2018

\section{References}

1. Bester J, Cole CM, Kodish E. The limits of informed consent for an overwhelmed patient: clinicians' role in protecting patients and preventing overwhelm. AMA J Ethics. 2016;18:869.

2. Barry MJ, Edgman-Levitan S. Shared decision making - the pinnacle of patient-centered care. N Engl J Med. 2012;366:780-1.

3. Girgis A, Sanson-Fisher RW. Breaking bad news: consensus guidelines for medical practitioners. J Clin Oncol. 1995;13:2449-56.

4. Salkeld G, Solomon M, Short L, Butow PN. A matter of trust-patient's views on decision-making in colorectal cancer. Health Expect. 2004;7:104-14

5. Shin DW, Cho J, Roter DL, Kim SY, Sohn SK, Yoon MS, Kim YW, Cho B, Park $\mathrm{JH}$. Preferences for and experiences of family involvement in cancer treatment decision-making: patient-caregiver dyads study. Psycho-Oncology. 2013;22:2624-31.

6. Goold S, Williams B, Arnold RM. Conflicts regarding decisions to limit treatment: a differential diagnosis. JAMA. 2000;283:909-14.

7. National Health and Medical Research Council: clinical practice guidelines for the management of early breast cancer. 2nd ed. Prepared by the iSource National Breast Cancer Centre; 2001.

8. Herrmann A, Sanson-Fisher R, Hall A, Wall L, Zdenkowski N, Waller A. A discrete choice experiment to assess cancer patients' preferences for when and how to make treatment decisions. Support Care Cancer. 2018;26:1215-20.

9. Louviere JJ. Choice experiments: an overview of concepts and issues. In: Bennett J, Blamey R, editors. The choice modelling approach to environmental valuation. Cheltenham: Edward Elgar Publishing; 2001. p. 13-36.

10. Viney R, Lancsar E, Louviere J. Discrete choice experiments to measure consumer preferences for health and healthcare. Expert Rev Pharmacoecon Outcomes Res. 2002;2(4):319-26.
11. Jones LG, Hawkins GE, Brown SD. Using best-worst scaling to improve psychological service delivery: an innovative tool for psychologists in organized care settings. Psychol Serv. 2015;12:20-7.

12. Kjær T. A review of the discrete choice experiment-with emphasis on its application in health care. Denmark: Syddansk Universitet; 2005.

13. Hol L, de Bekker-Grob EW, van Dam L, Donkers B, Kuipers EJ, Habbema JDF, Steyerberg EW, van Leerdam ME, Essink-Bot ML. Preferences for colorectal cancer screening strategies: a discrete choice experiment. Br J Cancer. 2010;102:972.

14. Sculpher M, Bryan S, Fry P, de Winter P, Payne H, Emberton M. Patients' preferences for the management of non-metastatic prostate cancer: discrete choice experiment. BMJ. 2004;328:382.

15. Ryan M. Discrete choice experiments in health care. BMJ. 2004;328:360-1.

16. Kimman ML, Dellaert BGC, Boersma LJ, Lambin P, Dirksen CD. Follow-up after treatment for breast cancer: one strategy fits all? An investigation of patient preferences using a discrete choice experiment. Acta Oncol. 2010;49:328-37.

17. Schofield PE, Butow PN, Thompson JF, Tattersall MHN, Beeney LJ, Dunn SM. Psychological responses of patients receiving a diagnosis of cancer. Ann Oncol. 2003;14:48-56.

18. Mead N, Bower P. Patient-centredness: a conceptual framework and review of the empirical literature. Soc Sci Med. 2000;51:1087-110.

19. Ajzen I. The theory of planned behavior. Organ Behav Hum Decis Process. 1991:50:179-211.

20. Fishbein M, Ajzen I. Belief, attitude, intention, and behavior: an introduction to theory and research. Philos Rhetor. 1977;10(2):130-2.

21. Zhang AY, Zyzanski SJ, Siminoff LA. Differential patient-caregiver opinions of treatment and care for advanced lung cancer patients. Soc Sci Med. 2010;70:1155-8.

22. Stewart M, Brown JB, Donner A, McWhinney IR, Oates J, Weston WW, Jordan J. The impact of patient-centered care on outcomes. J Fam Pract. 2000;49:796-804.

23. Siminoff $L A$. Incorporating patient and family preferences into evidencebased medicine. BMC Med Inform Decis Mak. 2013;13:S6.

24. Stiggelbout AM, Jansen SJT, Otten W, Baas-Thijssen MCM, van Slooten H, van de Velde CJH. How important is the opinion of significant others to cancer patients' adjuvant chemotherapy decision-making? Support Care Cancer. 2007;15:319-25.

25. Kühberger A, Schulte-Mecklenbeck M, Perner J. Framing decisions: hypothetical and real. Organ Behav Hum Decis Process. 2002;89:1162-75.

26. Telser $H$, Zweifel P. Validity of discrete-choice experiments evidence for health risk reduction. Appl Econ. 2007;39:69-78.
Ready to submit your research? Choose BMC and benefit from:

- fast, convenient online submission

- thorough peer review by experienced researchers in your field

- rapid publication on acceptance

- support for research data, including large and complex data types

- gold Open Access which fosters wider collaboration and increased citations

- maximum visibility for your research: over $100 \mathrm{M}$ website views per year

At BMC, research is always in progress.

Learn more biomedcentral.com/submissions 